\title{
Perbedaan Skor INA-MOCA pada Pemain Catur dan Bukan Pemain Catur
}

\author{
${ }^{1}$ Scivo V. Pauran \\ ${ }^{2}$ Junita Maja P. S. \\ ${ }^{2}$ Herlyani Khosama
}

\author{
${ }^{1}$ Kandidat Skripsi Fakultas Kedokteran Universitas Sam Ratulangi Manado \\ ${ }^{2}$ Bagian Neurologi Fakultas Kedokteran Universitas Sam Ratulangi Manado \\ Email: scivovictorio@gmail.com
}

\begin{abstract}
Aging is progressive declining process of many body functions, including cognitive function. Cognitive function is a conscious mental activity such as thinking, memory, learning, as well as language, and can be evaluated by using INA-MoCA. Chess is a popular game that requires intelligence. Some researchers believe that there is a close relation between cognitive function and chess. This study was aimed to determine whether there was any difference between the cognitive function of chess players and non-chess player. This was an analytic study with a cross-sectional study. Primary data were obtained from INA-MoCA score of the chess players and non-chess players. The results showed that in non-elderly category, the average score of INA-MoCA indicated that chess players had higher cognitive functions than non-chess players $(\mathrm{p}=0.43)$. In elderly category, the average score of INA-MoCA indicated that the chess players had better cognitive function than the non-chess players by 2.77 ( $\mathrm{p}=0.03$ ). Conclusion: Either elderly or non-elderly, chess players had higher cognitive function than non-chess players.
\end{abstract}

Keywords: cognitive function, elder, chess, INA-MoCA

\begin{abstract}
Abstrak: Menua adalah proses penurunan banyak fungsi tubuh yang progresif, termasuk penurunan kognitif. Fungsi kognitif adalah aktivitas mental secara sadar seperti berpikir, mengingat, belajar, dan bahasa. Salah satu evaluasi fungsi kognitif dengan menggunakan INA-MoCA. Permainan catur merupakan permainan yang populer dan memerlukan kecerdasan. Beberapa peneliti percaya bahwa ada hubungan yang erat antara fungsi kognitif dan permainan catur. Penelitian ini bertujuan untuk mengetahui apakah terdapat perbedaan fungsi kognitif antara pemain catur dan bukan pemain catur. Jenis penelitian ialah analitik dengan desain potong lintang. Data primer ialah skor INA-MoCA pemain catur dan bukan pemain catur. Hasil penelitian pada kelompok bukan lansia, rerata skor INA-MoCA mengindikasikan pemain catur memiliki fungsi kognitif yang lebih tinggi daripada yang bukan pemain catur $(\mathrm{p}=0,43)$. Pada kelompok lansia, rerata skor INA-MoCA menunjukan pemain catur memiliki fungsi kognitif yang lebih baik daripada bukan pemain catur dengan selisih 2,77 $(\mathrm{p}=0,03)$. Simpulan: Fungsi kognitif pemain catur baik pada lansia maupun bukan lansia lebih baik daripada bukan pemain catur.
\end{abstract}

Kata kunci: fungsi kognitif, lansia, pemain catur, INA-MoCA

Menua adalah suatu proses menghilangnya secara perlahan-lahan kemampuan jaringan untuk memperbaiki/mengganti diri dan mempertahankan struktur dan fungsi normalnya sehingga tidak dapat bertahan terhadap jejas dan memperbaiki kerusakan yang diderita. Salah satu fungsi yang terkena dampak penuaan ialah fungsi kognitif yang mengacu pada kemampuan seseorang untuk memroses pikiran. ${ }^{1}$ 
Kognitif terutama mengacu pada hal-hal seperti memori, kemampuan untuk mempelajari informasi baru, berbicara, pemahaman membaca, sednagkan fungsi eksekutif ialah kemampuan kognitif tinggi seperti cara berpikir dan kemampuan pemecahan masalah. ${ }^{2}$ Domain fungsi kognitif meliputi atensi (pemusatan perhatian), bahasa, memori, visuospasial atau pengenalan ruang dan fungsi eksekutif yang dapat didefinisikan sebagai suatu proses kompleks seseorang ketika memecahkan masalah. Penurunan fungsi kognitif pada lansia bisa diperlambat dengan brain exercise, misalnya dengan bermain catur. ${ }^{3,4}$ Beberapa penelitian melaporkan, bermain catur tampaknya melibatkan aktivitas lobus oksipitalis dalam hal pemrosesan visual dan aktivasi lobus parietalis dalam hal orientasi spasial. ${ }^{5}$ Pada pemain amatir, bermain catur tampaknya melibatkan aktivasi lobus temporal medial dan hipokampus dalam hal analisis informasi papan catur sebagai pembelajaran dan memorizing sedangkan pada para pemain profesional, bermain catur tampaknya melibatkan aktivasi lobus frontalis yang menunjukkan penalaran tingkat tinggi dan perencanaan langkah, dan pemanfaatan ingatan dalam memilih taktik yang jitu. Meskipun demikian, brain exercise hanya bisa memperlambat penurunan fungsi kognitif.,

Pada lansia yang umumnya mengalami penurunan fungsi kognitif, dapat dilakukan evaluasi salah satunya dengan menggunakan Montreal Cognitive Assesment (MoCA). MoCA terdiri dari 30 poin yang akan diujikan dengan menilai beberapa domain kognitif, yaitu fungsi eksekutif (1 poin); visuospasial (4 poin); bahasa (6 poin); atensi (6 poin); abstraksi (2 poin), memori (5 poin); orientasi ( 6 poin). ${ }^{8}$

\section{METODE PENELITIAN}

Jenis penelitian ini ialah analitik dengan desain potong lintang. Penelitian dilakukan di Jalan Roda, pasar 45 Manado, di pasar Karombasan Manado ,dan di desa Winorangian, Kecamatan Tombatu Utara, Minahasa Tenggara, Sulawesi Utara.
Penelitian ini dilakukan selama 3 bulan, dimulai pada bulan November 2015 dan berakhir pada bulan Januari 2016. Subyek penelitian ialah pemain catur usia 45-60 dan lansia, serta bukan pemain catur usia 45-60 dan lansia.

\section{HASIL PENELITIAN}

Pada penelitian ini didapatkan 60 subyek penelitian. Tabel 1 menunjukkan bahwa riwayat pendidikan kebanyakan berada di bawah 12 tahun (75\%). Untuk riwayat penyakit persentase terbesar ialah hipertensi (32\%), kemudian penyakit jantung (14\%). Penyakit-penyakit lainnya memiliki persentase $21 \%$ dan yang tidak memiliki riwayat penyakit memiliki persentase $33 \%$. Mengenai merokok, sebagian besar subjek (78\%) mengaku perokok aktif sedangkan lainnya (22\%) bukan perokok.

Tabel 2 menunjukkan rerata komponen fungsi visuospasial/eksekutif pada pemain catur lebih tinggi daripada bukan pemain catur dengan selisih 0,24. Demikian juga terjadi pada komponen memori/delayed recall dengan selisih 0,12 dan komponen bahasa dengan selisih 0,36 . Namun pada komponen abstraksi dan orientasi, yang bukan pemain catur memiliki rerata yang lebih tinggi daripada pemain catur, yaitu dengan selisih 0,12 dan 0,05. Dari rerata skor, pemain catur memiliki rerata lebih tinggi dengan selisih 0,53 . Nilai $p=0,43$ $(>0,05)$ menunjukkan bahwa perbandingan rerata antara pemain catur dan bukan pemain catur kelompok bukan lansia tidak bermakna.

Tabel 3 menunjukkan secara keseluruhan bahwa fungsi kognitif pemain catur lebih baik darpada yang bukan pemain catur kelompok lansia. Dimulai dengan kompenen visuospasial/eksekutif dengan selisih 0,92. Kemudian berturutturut komponen penamaan, memori, atensi, bahasa, abstraksi, orientasi dengan selisih $0,23,1,0,0,23,0,16,0,23$, dan 0,38. Dari rerata skor, dapat dilihat selisih yaitu 2,77. Nilai p yang diperoleh ialah $0,03(<0,05)$ yang berarti perbandingan hasil tes fungsi kognitif bermakna. 
Pauran, Maja, Khosana: Perbedaan skor INA-MOCA...

Tabel 1. Karakteristik penelitian secara umum

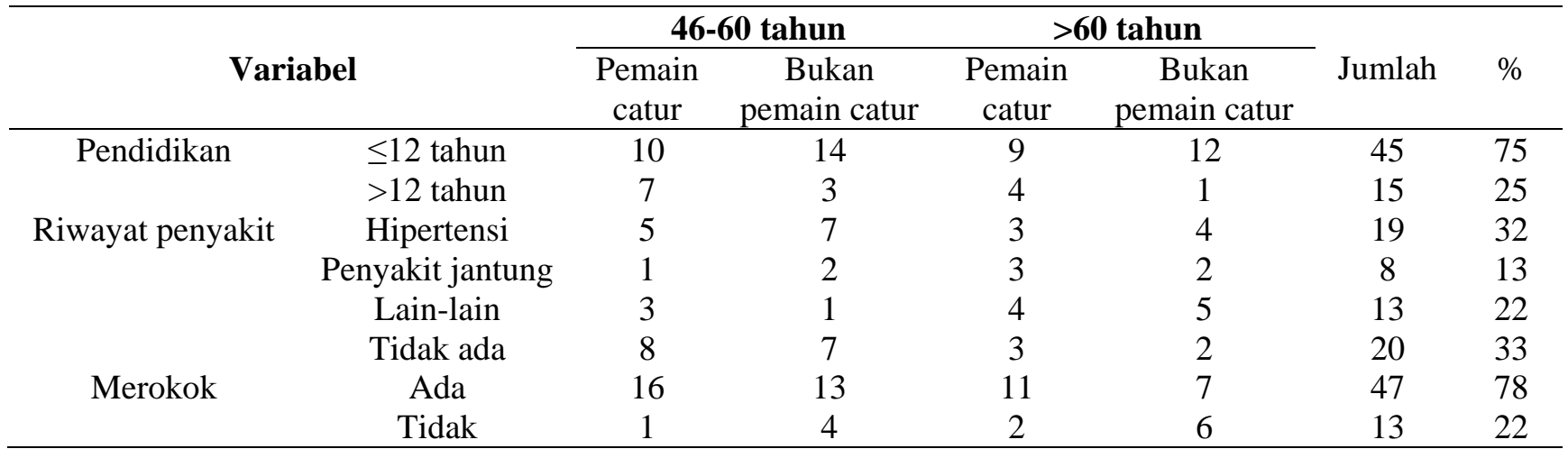

Tabel 2. Perbandingan komponen-komponen fungsi kognitif kelompok bukan lansia dari hasil tes INA MoCA.

\begin{tabular}{|c|c|c|c|c|c|c|c|c|c|}
\hline \multirow[b]{2}{*}{$\begin{array}{l}\text { Bukan } \\
\text { lansia }\end{array}$} & \multicolumn{7}{|c|}{ Komponen fungsi kognitif INA MoCA (mean) } & \multirow{2}{*}{$\begin{array}{c}\text { Rerata } \\
\text { skor tes } \\
\text { INA } \\
\text { MoCA }\end{array}$} & \multirow[b]{2}{*}{$\begin{array}{c}\text { Nilai } \\
\mathrm{p}\end{array}$} \\
\hline & $\begin{array}{l}\text { Visuospasial/ } \\
\text { eksekutif }\end{array}$ & Penamaan & $\begin{array}{c}\text { Memori/ } \\
\text { delayed } \\
\text { recall }\end{array}$ & Atensi & Bahasa & Abstraksi & Orientasi & & \\
\hline $\begin{array}{c}\text { Pemain } \\
\text { catur }\end{array}$ & 4,82 & 3 & 4,64 & 4,58 & 2,88 & 1,29 & 5,71 & 27,47 & 0,43 \\
\hline $\begin{array}{c}\text { Bukan } \\
\text { pemain } \\
\text { catur }\end{array}$ & 4,58 & 3 & 4,52 & 4,29 & 2,52 & 1,41 & 5,76 & 26,94 & \\
\hline
\end{tabular}

Tabel 3. Perbandingan komponen-komponen fungsi kognitif kelompok lansia dari hasil tes INA MoCA.

\begin{tabular}{|c|c|c|c|c|c|c|c|c|c|}
\hline \multirow[b]{2}{*}{ Lansia } & \multicolumn{7}{|c|}{ Komponen fungsi kognitif INA MoCA (mean) } & \multirow{2}{*}{$\begin{array}{c}\text { Rerata } \\
\text { skor tes } \\
\text { INA } \\
\text { MoCA }\end{array}$} & \multirow[b]{2}{*}{ Nilai $\mathrm{p}$} \\
\hline & $\begin{array}{l}\text { Visuospasial/ } \\
\text { eksekutif }\end{array}$ & Penamaan & $\begin{array}{c}\text { Memori/ } \\
\text { delayed } \\
\text { recall }\end{array}$ & Atensi & Bahasa & Abstraksi & Orientasi & & \\
\hline $\begin{array}{c}\text { Pemain } \\
\text { catur }\end{array}$ & 4,69 & 3 & 4,38 & 3,92 & 2,54 & 1,31 & 5,69 & 26,15 & 0,03 \\
\hline $\begin{array}{c}\text { Bukan } \\
\text { pemain } \\
\text { catur }\end{array}$ & 3,77 & 2,77 & 3,38 & 3,69 & 2,38 & 1,08 & 5,31 & 23,38 & \\
\hline
\end{tabular}

\section{BAHASAN}

Fungsi kognitif adalah suatu kegiatan mental yang dimiliki manusia yang diantaranya adalah perhatian, persepsi, proses berpikir, pengetahuan, dan memori. Berdasarkan alat ukur INA MoCA, data demografi yang harus ada adalah usia, jenis kelamin, dan pendidikan. Menurut Mongisidi, ${ }^{9}$ individu yang masuk kategori old age (75-90 tahun) memiliki rerata persentase kognitif yang tidak normal. Pada Tabel 2, nilai p menunjukkan bahwa tidak ada perbedaan bermakna antara pemain catur dan bukan pemain catur sehingga bisa dikatakan tidak ada perbedaan antara fungsi kognitif antara pemain catur dan bukan pemain catur usia lansia. Meskipun begitu rerata skor menunjukkan bahwa tingkat kognitif pemain catur lebih unggul daripada yang tidak bermain catur. Pemain catur juga unggul pada beberapa komponen seperti visuospasial/eksekutif, fungsi memori/delayed recall, atensi dan bahasa, tetapi pada fungsi abstraksi dan orientasi rerata pemain catur kalah dibandingkan dengan bukan pemain catur. Pada Tabel 3, nilai $\mathrm{p}$ menunjukkan adanya perbedaan bermakna antara pemain catur dan bukan pemain catur usia lansia yang berarti dibandingan dengan yang tidak bermain 
catur, orang yang memiliki kebiasaan bermain catur mampu memiliki tingkat fungsi kognitif yang lebih tinggi. Beberapa penelitian telah dilakukan mengenai efek permainan catur pada individu menyatakan bahwa pemain catur memiliki keunggulan dalam memecahkan masalah, mengembangkan memori, dan pemusatan perhatian. 10,11

\section{SIMPULAN}

Dari hasil penelitian dapat disimpulkan bahwa pada kelompok bukan lansia, terdapat perbedaan rerata skor INA-MoCA antara pemain catur dan bukan pemain catur yang tidak bermakna, sedangkan pada kelompok lansia terdapat perbedaan bermakna antara pemain catur dan bukan pemain catur yang menunjukkan bahwa pemain catur memiliki fungsi kognitif yang lebih baik.

\section{SARAN}

Disarankan sosialisasi untuk bermain catur sejak dini sebagai brain exercise agar supaya proses penurunan fungsi kognitif bisa diperlambat. Penelitian lebih lanjut perlu dilakukan dengan subyek penelitian yang lebih banyak untuk mengetahui faktor-faktor yang memengaruhi fungsi kognitif pada pemain catur maupun yang bukan pemain catur.

\section{DAFTAR PUSTAKA}

1. Peters KE. Implications of the aging process: Opportunities for preventions. Illinois: Illinois Prevention Research Center, 2007; p. 1-3.

2. Mardjono M, Sidharta P. Neurologis Klinis Dasar (6th ed). Jakarta: Dian Rakyat, 1994; p. 203.

3. Sibarani R. Perbandingan akurasi diagnostik antara cognitive performance scale dan mini mental state examination terhadap general practioner assessment of cognition untuk menilai fungsi kognitif pada usia lanjut. [Universitas Sumatera Utara. Bab 2 Tinjauan Pustaka]. [cited 2015 Oct 25]. Available from: http://repository.usu.ac.id/bitstream/12
3456789/41458/4/Chapter\%20II.pdf.

4. Hill EJ. What is cognitive function? wiseGEEK [cited 2012 Oct 15]. Available from URL: http://wisegeek. com/what-is-cognitive-function.htm\#

5. Atherton M, Zhuang J, Bart WM, Hu X, He S. A functional MRI study of highlevel cognition. The game of chess. Cognitive Brain Research. [cited 2015 Oct 24]. Available from URL: http://sheng-lab.psych.umn.edu/ pdf_files/Atherton_fMRI_chess.pdf

6. Ferguson RC. Teacher guides: Research and benefits of chess. [cited 2015 Oct 25]. Available from URL: http://www. quadcitychess.com/benefits_of_chess. html

7. Urra JC. Cognitive test battery to evaluate the executive functions to chess players. Revista Digital [cited 2015 Oct 24]. Available from URL: http://www.efdeportes.com/efd204/ev aluate-the-executive-functions-tochess-players.htm

8. Panentu D, Irfan M. Uji validitas dan reliabilitas butir pemeriksaan dengan Montral Cognitive Assesment versi Indonesia (INA-MoCA) pada insan pasca recovery. [cited 2015 Oct 25]. Available from URL: http:// ejurnal.esaunggul.ac.id/index.php/Fisi o/article/download/646/607

9. Mongisidi R. Profil penurunan fungsi kognitif pada lansia di yayasanyayasan manula Kecamatan Kawangkoan [cited 2016 January 15]. Available from URL: http:// ejournal.unsrat.ac.id/index.php/eclinic/ article/view/3297/2840

10. Kazemi F, Yektayar M, Abad AM. Investigation the impact of chess play on developing meta-cognitive ability and math problem-solving power of students at different levels of education [cited 2016 January 18]. Available from URL: http:// www.sciencedirect.com/science/article /pii/S1877042812000572

11. Nejati MV. Frontal lobe function in chess player. Acta Medica Iranica. [cited 2015 Oct 2015]. Available form URL : http://applications.emro.who.int/ imemrf/Acta_Med_Iran/Acta_Med_Ir an_2012_50_5_311_314.pdf. 